\title{
Construction on Item Bank of Listening Comprehension for College Japanese Four-grade Examination
}

\author{
Liming Wang \\ College of Foreign Languages, Bohai University, Jinzhou, 121013, China \\ 2860333710@qq.com
}

\begin{abstract}
Keywords: college Japanese; four-grade examination; listening comprehension; item bank; data structure design
\end{abstract}

\begin{abstract}
Listening is an important part of learning a foreign language, listening comprehension is one of the college Japanese four-grade examination questions. In view of the low scoring rate of students, the construction of the four-grade of college Japanese listening comprehension questions, and provide more listening training opportunities for students. First, the research of listening teaching methods, such as stage training, micro skills, modern facilities; Next, the data structure design, based on SQL Server design the structure of the table; then, create a database, study the creation process and the related documents; finally, in the database created the data table. The construction of item bank plays an important role in the theoretical research and teaching practice. The research results of this paper will play a positive role in improving students' listening level and four-grade test scores.
\end{abstract}

\section{Introduction}

College Japanese listening course teaching is classified into two school year opened, after listening training of the first school year, students should meet the following requirements: can understand in the listening materials familiar themes related to the more simple speech and everyday life conversations, can catch the drift of speech and conversation, can identify the speaker's attitude and tone, able to listen to the key points of the material and in Japanese as the brief notes, Japanese listening level has reached at least the three levels of the Japanese language proficiency test level. After listening training of the second school year, students should meet the following requirements: be able to understand lengthy article of listening textbooks, to seize the main content of the article, and can be expressed or repeat central meaning of the article in Japanese; can understand Japanese radio programs, news, and so on, can catch the central meaning of the broadcast program and the news; and be able to listen to the key points of material used in Japanese for more detailed notes, Japanese listening level is at least two levels of the Japanese language proficiency test level [1,2 ].

College Japanese teaching aim is to cultivate students with strong reading ability, a certain listening and writing ability, the initial writing and speaking ability, so that students can take the Japanese as a tool to get professional and required information, and to further improve the level of Japanese to lay a good foundation. According to the provisions of "College Japanese Teaching Syllabus", the completion of four, six levels students needs to carry on nationwide unified standardized tests. College Japanese four-grade test is designed in accordance with this provision, the purpose is by this means of the exam, to assess comprehensively have been completed student of college Japanese four levels, whether these students achieve the each targets specified in syllabus. Through the construction of the college Japanese listening comprehension item bank, to provide more training opportunities for students, to improve the college Japanese four- grade pass rate service.

\section{Listening Teaching Methods}

In the field of listening research, there are two kinds of views on the process of listening comprehension, that is, "bottom-up" model and the "top-down" model. "Bottom-up" model that the listening is the process of sound decoding, stressed the important role of language knowledge in 
listening comprehension, but ignored the important role of background knowledge of listening learner for listening comprehension; "bottom-up" model is in the surface of vocabulary, syntax, semantics layer for listening material on "finishing", is a process of sounds-words-sentences, listeners use their background knowledge, understanding listening article structure and knowledge of the world, and other help themselves understand the original listening. "Bottom-up" and "top-down" models have their advantages and disadvantages, in practice, to play the advantages and avoid inadequate. Usually can take the following teaching method [3,4]:

(1) Note that the stage of listening teaching. When the teacher during the listening teaching, the basic situation of the students to understand, which has targeted to train students' listening skills. Listening comprehension is about five stages. The first stage, the students hear a bunch of sound, there is no understanding of the content; the second stage, students can identify some isolated, content associated with the word in a string of sound; the third stage, students in the speech flow identify a phrase or sentence, and by the phrase or sentence have a general understanding of the conversation in the most basic of everyday life; the fourth stage, students can identify in the language stream clauses or sentences, and know the meaning, the content of the talk has a general understanding; fifth stage, students can understand the talk coherent content.

(2) Strengthen the cultivation of micro listening skills. Predictive ability is also a very important listening micro skill. In daily communication, people can predict the words and their meanings by the context of the speaker. Cultivation predictive ability includes more aspects. Before the start of the listening training, teacher by asking questions and listening material related or introduce the relevant background knowledge, inspire students' thinking, and students have a clear understanding for listening training purposes and requirements. This allows students to take the issue into actively listening training activities. Teachers can also train students' predictive ability in the pronunciation and intonation. Pronunciation and intonation is one of an important means to express the meaning of the speaker, the hearer to predict the next meaning of the phrase by the speaker's tone of voice.

(3) Note that the listening teaching and other skills teaching combined. From the perspective of language evolution and the reality of language communication, listening comprehension plays a vital role in human language communication. From the perspective of language acquisition, language or linguistic components is an important step in the process of second language acquisition, and listening comprehension skills in other languages skills obtained and improve plays an important role. Teachers should combine to develop listening ability and develop other skills; in the premise of the cultivation of listening skills promote the cultivation of other skills.

(4) Full use of modern audio-visual equipment and learning conditions. Many colleges and universities have a more advanced multimedia classroom or language laboratory. As if only the playback, listening and doing exercises place is a waste of resources. We should make full use of the facilities in which such player, VCD or DVD, movies, television and listening or audiovisual teaching film specially prepared for listening or audiovisual courses. In the teaching of listening, the use of audio-visual materials can make the combination of sound and image, visual and auditory combination, language and scene combination, to the visual, auditory, and other types of learning seriously preparing lessons. The language and cultural difficulties in the materials should be designed to help preheat interesting audio-visual training exercises or tasks. Harmer points out, in addition to listening should use some common tasks or exercises, and the use of a form of exercise that is suitable for audio-visual materials should be noted.

\section{Data Structure Design}

Data structure is the way to store and organize data. Data structure is a collection of data elements that exist in one or more specific relationships. Typically, carefully selected data structures can bring higher operating or storage efficiency. In the field of specific software development, data structure design is usually closely related to the specific database management systems $[5,6]$. This paper selects Server SQL database management system.

SQL Server is Microsoft's launch of the relational database management system, is a comprehensive database platform, using integrated business intelligence tools provide 
enterprise-class data management, it has the advantages of easy to use, good scalability and a high degree of integration with related software. It can be across from running Microsoft Windows 98 laptop to running Microsoft Windows 2012 large multi-processor servers, and a variety of platforms to use. Microsoft SQL Server database engine is relational and structured data to provide a more secure and reliable storage function, and can build and manage highly available and high-performance data applications for business.

There are three entities in this system, namely "Listening Test Questions Type", "Listening Test Questions Topic" and "Listening Test Questions Topic Option". Wherein, "Listening Test Questions Type" entity and "Listening Test Questions Topic" entity is the relation of one to many, one type exist many test questions, a test question can only belong to one type; "Listening Test Questions Topic" entity and "Listening Test Questions Topic Option" entities are the relation of many to one, that a test question exist a number of options, one option can only belong to a test question. Data structure design based on SQL Server database management system, the results is shown in Table 1.

Table 1. Data structure item bank of listening comprehension for college japanese four-grade examination

\begin{tabular}{|c|c|c|c|c|c|c|c|}
\hline \multicolumn{4}{|c|}{ " ListeningTestQuestionsType" Table } & 12 & ChineseContent & text & 16 \\
\hline 1 & ID & varchar & 20 & 13 & MediaType & varchar & 10 \\
\hline 2 & TestQuestionsTypeCode & char & 1 & 14 & PictureName & varchar & 100 \\
\hline 3 & TestQuestionsTypeName & varchar & 30 & 15 & PictureStore & varbinary & 50 \\
\hline 4 & Remarks & text & 16 & 16 & TestQuestionsScores & tinyint & 1 \\
\hline \multicolumn{4}{|c|}{ "ListeningTestQuestionsTopic" Table } & 17 & AnswerOption & char & 1 \\
\hline 1 & ID & varchar & 20 & 18 & AnswerEssentials & text & 16 \\
\hline 2 & TestQuestionsNo & varchar & 20 & 19 & Remarks & text & 16 \\
\hline 3 & InBankDate & datetime & 10 & \multicolumn{4}{|c|}{ " ListeningTestQuestionsTopicOption" Table } \\
\hline 4 & InBankTime & datetime & 18 & 1 & ID & varchar & 20 \\
\hline 5 & InBankPeopleName & varchar & 30 & 2 & TestQuestionsNo & varchar & 20 \\
\hline 6 & InBankPeopleName & char & 5 & 3 & OptionCode & char & 1 \\
\hline 7 & DifficultyCoefficient & decimal & 4,2 & 4 & OptionContent & varchar & 500 \\
\hline 8 & TestQuestionsSource & varchar & 50 & 5 & ChineseContent & varchar & 500 \\
\hline 9 & TestQuestionsTitle & varchar & 200 & 6 & PictureName & varchar & 100 \\
\hline 10 & ChineseTitle & varchar & 200 & 7 & PictureStore & varbinary & 50 \\
\hline 11 & TestQuestionsContent & text & 16 & 8 & BriefDescription & text & 16 \\
\hline
\end{tabular}

\section{Create Database}

Create a database in SQL Server requires at least clear the following information: the database name, data sorting method, database size, database storage location, for the file name stored in the database included information and so on. There are several ways to create the database, usually SSMS (SQL Server Management Studio) provides a graphical interface and SQL statements two ways, this paper use SQL statements to create, and the statement is as follows:

Database created above, including "JapaneseItemBank_Data.MDF" and "JapaneseItemBank_Log.LDF" two files. Each SQL Server database has at least two operating system files: a data file and a log file. Data files contain data and objects, such as tables, indexes, stored procedures, and views. The log file contains the required information about all the transactions of restore the database. In order to facilitate the distribution and management, the data files can be set up into file groups. The main data file contains the startup information of databases 
and points to other files in the database. User data and objects can be stored in the file, and can be stored in the secondary data file. Each database has a primary data file. Recommendations document extension of main data file is "MDF"; transaction log files saved for recovery $\log$ information in the database. Each database must have at least one log file. It recommends that the transaction log file extension is "LDF". Data and log files initial size is $1 \mathrm{MB}$, files automatically increase by $10 \%$, and the size of the file increase is not limited.

Creating a database using the "CREATE DATABASE" statements, which mainly includes three parameters: (1) ON, description data file placement and name, and the name, size and growth of data files, respectively, using "NAME, FILENAME, SIZE, FILEGROWTH" and other keywords; (2) LOG ON, description information of the log file, description method, keyword and data file are same; (3) COLLATE, described collation used by the database, this database using "Albanian_BIN", according to each character defined bit pattern for the data of SQL Server tables to sort and compare. Both binary sort orders are case-sensitive, but also to distinguish stress. Binary sort order is also the fastest.

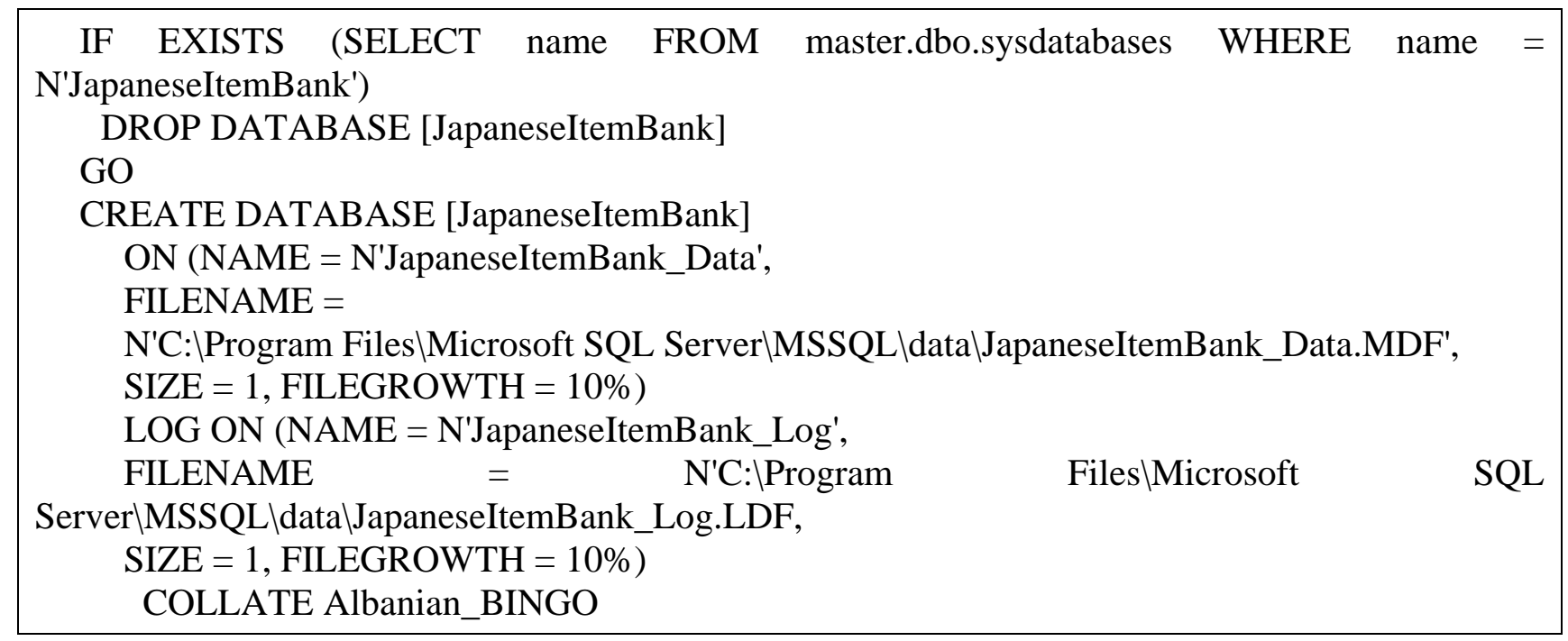

\section{Create Data Table}

Data table (referred to as table) is a very important object in the database, and it is the basis of other objects. Database is only a framework. Data table is its essence. According to the classification of information, a database may contain a number of data tables. "JapaneseItemBank" database contains "ListeningTestQuestionsType, ListeningTestQuestionsTopic, ListeningTestQuestionsTopicOption" the three tables. There are many ways to build a database table, usually using SSMS (SQL Server Management Studio) provides a graphical interface and SQL statements in two methods, the paper use SQL statements to create, with the "ListeningTestQuestionsTopic" table, for example, create the statement is as follows: 


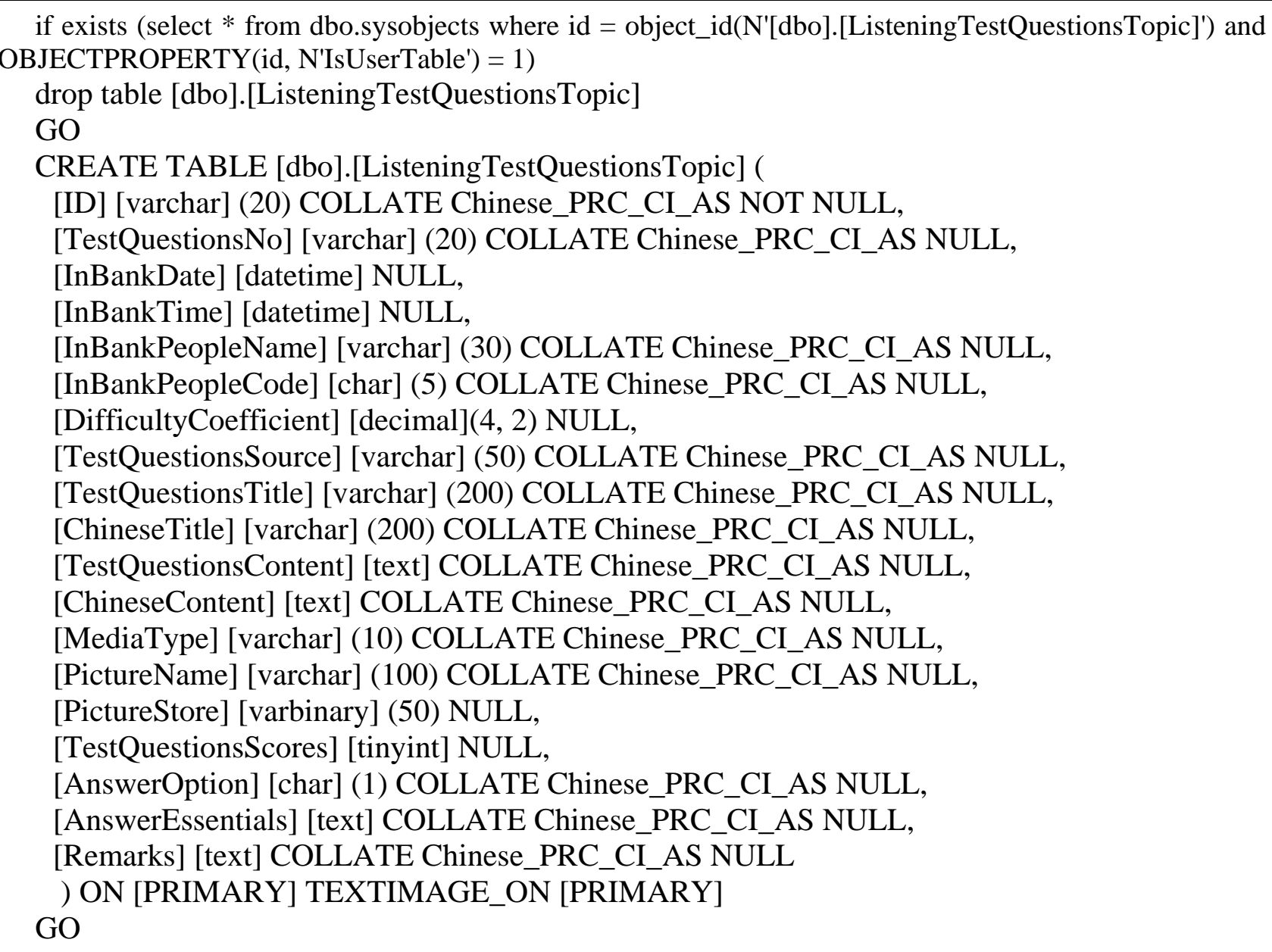

\section{Conclusion}

In foreign language learning, the main is to cultivate "listening", " speaking ", "reading" and "writing" four basic skills. Listening is in the first place, the importance of listening is the unusual. People in linguistic communication $45 \%$ of the time for listening, speaking accounted for $30 \%$, read accounted for $16 \%$ and write accounted for $9 \%$. Thus to learn a foreign language, not only to train reading and writing skills, but also to pay attention to listening and speaking skills. The construction and management of the examination question bank plays an important role in theoretical research and teaching practice. Question bank building is a means to improve the college Japanese teaching, improve teaching quality is the goal [7]. In practical application process to timely teaching evaluation, pay attention to analyze student feedback [8], for the application effect constantly adjust, enrich the content of the question bank, for students to improve their Japanese language listening ability and college Japanese four-grade test scores will play an active role.

\section{References}

[1] L. Luo, "Test Band 4 for Japanese Majors and Japanese Listening Teaching," Journal of Mudanjiang College of Education, vol. 30, no. 3, pp. 116-117, 2014.

[2] H. F. Wei, "An analysis of the four levels of Japanese test and teaching in College," Journal of Kaifeng Institute of Education, vol. 34, no. 9, pp. 91-92, 2014.

[3] Y. H. Lu, "Application of task based approach in English Listening Teaching," Education Review, vol. 30, no. 1, pp. 120-122, 2014. 
[4] M. J. Shi, "An empirical study on the relationship between strategy use level and professional level four grades of the Japanese Learning," Journal of Nanchang College of Education, vol. 28, no. 4, pp. 170-171, 2013.

[5] Y. J. Lin, "Research on Key Technology of Performance Optimization for Database Logical Structure Design," Computer technology and development, vol. 23, no. 12, pp. 74-77, 2013.

[6] J. Q. Mo, Y. H. Lin, "Design and implementation of test library management system based on .NET," Computer Era, vol. 32, no. 10, pp. 78-80, 2014.

[7] Y. L. Luo, Y. F. Jia, "Application of project response theory in the construction of question bank," Computer Applications and Software, vol. 32, no. 1, pp. 86-88, 2015.

[8] K. Liu, "To explore new mode of intensive reading teaching from the Japanese professional examination," Journal of Jiamusi Education Institute, vol. 31, no. 4, pp. 328-329, 2014. 